\title{
Growth rates and the prevalence and progression of scoliosis in short-statured children on Australian growth hormone treatment programmes
}

\author{
Gregory A Day*1,3, Ian Bruce McPhee ${ }^{1}$, Jenny Batch ${ }^{2}$ and \\ Francis H Tomlinson ${ }^{1}$
}

Address: ${ }^{1}$ Department of Surgery, University of Queensland, Brisbane, Australia, ${ }^{2}$ Department of Paediatrics and Child Health, University of Queensland, Brisbane, Australia and ${ }^{3}$ Level 5, St Andrews Place, 33 North Street, Spring Hill, Queensland, Australia 4000

Email: Gregory A Day* - ggandlda@bigpond.net.au; Ian Bruce McPhee - i.mcphee@uq.edu.au; Jenny Batch - jenny_batch@health.qld.gov.au; Francis H Tomlinson - f.tomlinson@uq.edu.au

* Corresponding author

Published: 22 February 2007

Scoliosis 2007, 2:3 doi:10.1186/1748-7161-2-3

This article is available from: http://www.scoliosisjournal.com/content/2/1/3

(c) 2007 Day et al; licensee BioMed Central Ltd.

This is an Open Access article distributed under the terms of the Creative Commons Attribution License (http://creativecommons.org/licenses/by/2.0), which permits unrestricted use, distribution, and reproduction in any medium, provided the original work is properly cited.
Received: 3 August 2006

Accepted: 22 February 2007

\begin{abstract}
Study design and aim: This was a longitudinal chart review of a diverse group (cohort) of patients undergoing HGH (Human Growth Hormone) treatment. Clinical and radiological examinations were performed with the aim to identify the presence and progression of scoliosis.

Methods and cohort: 185 patients were recruited and a database incorporating the age at commencement, dose and frequency of growth hormone treatment and growth charts was compiled from their Medical Records. The presence of any known syndrome and the clinical presence of scoliosis were included for analysis. Subsequently, skeletally immature patients identified with scoliosis were followed up over a period of a minimum four years and the radiologic type, progression and severity (Cobb angle) of scoliosis were recorded.

Results: Four (3.6\%) of the 109 with idiopathic short stature or hormone deficiency had idiopathic scoliosis (within normal limits for a control population) and scoliosis progression was not prospectively observed. $13(28.8 \%)$ of 45 with Turner syndrome had scoliosis radiologically similar to idiopathic scoliosis. II (48\%) of 23 with varying syndromes, had scoliosis. In the entire cohort, the growth rates of those with and without scoliosis were not statistically different and HGH treatment was not ceased because of progression of scoliosis.

Conclusion: In this study, there was no evidence of HGH treatment being responsible for progression of scoliosis in a small number of non-syndromic patients (four). An incidental finding was that scoliosis, similar to the idiopathic type, appears to be more prevalent in Turner syndrome than previously believed.
\end{abstract}

\section{Background}

Research indicating that juveniles who develop idiopathic scoliosis have a markedly elevated growth rate compared to controls fostered a popular belief that growth hormone influences the progression of scoliosis[1,2]. Serum levels of growth hormone in children with idiopathic scoliosis 
Table I: Syndromes/conditions known to be associated with scoliosis

\begin{tabular}{|c|c|c|}
\hline Diagnosis & Number of patients & Number with scoliosis \\
\hline Turner & 45 & 14 (I congenital) \\
\hline Vater & 2 & 2 \\
\hline Leri-Weill & 2 & 2 \\
\hline Russell Silver dwarf & 1 & 1 \\
\hline Klippel-Feil with Sprengel shoulder & I & I \\
\hline Pierre-Robin & 1 & 0 \\
\hline Stickler's & 1 & 0 \\
\hline Noonan & 1 & 0 \\
\hline Dubowitz & 1 & 0 \\
\hline Neurofibromatosis & 1 & 0 \\
\hline Cerebral Palsy & I & 1 \\
\hline Spina Bifida & 1 & 1 \\
\hline Multiple seizures & 1 & 0 \\
\hline Cysteinosis & I & 0 \\
\hline Fanconi Syndrome and Rickets & 1 & I \\
\hline Pituitary Deep Xray therapy & 1 & 1 \\
\hline Downs & 1 & I \\
\hline Congenital rubella & 1 & 0 \\
\hline Deep Xray therapy to the brain & 4 & 0 \\
\hline
\end{tabular}

were found to be elevated between the ages of seven and twelve years compared to controls [3-7]. Progression of structural scoliosis was reported in a short-statured patient during Human Growth Hormone (HGH) treatment [8] and stimulated a systematic clinical audit of children with scoliosis on an HGH treatment programme in one institution [9]. The administration of HGH appeared to accelerate the progression of scoliosis in six of ten children on that programme (cohort size 250) [9]. Of the ten, five had idiopathic scoliosis, one had acute lymphocytic leukaemia and two with Turner syndrome were diagnosed with scoliosis prior to treatment. An accelerated growth rate was also recorded in eight of ten with scoliosis.

Armed with this information, it was hypothesized that children with scoliosis, who are administered Human Growth Hormone, are more likely to have progression of their scoliosis and an accelerated growth rate compared to those without scoliosis. The aims of this study are to determine the prevalence of scoliosis in four Australian Institutions' Growth Hormone Treatment Programmes and to confirm the results of previous research that HGH treat- ment can be associated with progression of pre-existing scoliosis.

\section{Methods and subjects \\ Study group}

298 medical records were available for scrutiny and 30 were excluded for reasons outlined in Exclusion criteria. A database was completed for 185 (69\%) of the remaining 268 patients. 83 (31\%) refused to complete the mailedout questionnaire and sign consent. Of the 185 patients, 97 had idiopathic short stature and 12 had either growth hormone or multiple pituitary hormone deficiency. 68 had a condition/syndrome known to be associated with scoliosis (Table 1). Eight patients had conditions not usually associated with scoliosis (Table 2).

\section{Exclusion criteria}

Exclusion criteria for clinical examination included five children less than six years old and nineteen who commenced the OZGROW (The Australasian Paediatric Growth Hormone database) programme over the age of twelve years, because of their proximity to menarche. Two

Table 2: Conditions other than idiopathic short stature, not usually associated with scoliosis

\begin{tabular}{ll}
\hline Diagnosis & Number of patients \\
\hline Renal failure & 3 \\
Polycystic kidney & $\mathrm{I}$ \\
Nephrotic syndrome & $\mathrm{I}$ \\
Glomerulo-nephritis & $\mathrm{I}$ \\
Arachnoid cyst & $\mathrm{I}$ \\
Gilbert's syndrome & \\
\hline
\end{tabular}


who signed Consent Forms and subsequently changed their minds were excluded. The Medical Records of four deceased were available for perusal, but were excluded from analysis.

\section{Database}

The age at examination, gender, growth charts (Stature for Age - developed by the National Centre for Health Statistics in conjunction with the National Centre for Chronic Disease Prevention and Health Promotion 2000), the timing (age of commencement) and dosage and frequency of growth hormone treatment and the presence, site and severity of any detected spinal deformity were recorded for all who underwent clinical examination (Additional file 1). Turner syndrome growth charts were used specifically for that syndrome [10]. Turner syndrome karyotypes were recorded (Table 3). Information from the medical records revealed the presence of any known spinal deformity prior to the commencement of the HGH treatment.

\section{Growth chart information}

Actual and percentile heights were recorded at three monthly intervals during the HGH treatment programme. Percentile, rather than actual, heights were included for analysis because the growth chart with actual heights for Turner syndrome has a different scale from the National Centre for Health Statistics scale.

\section{Clinical confirmation of spine deformity}

Patients presented dressed in a white Hospital gown for a forward bend test (Adams), having removed their shoes [11]. One examiner (GD) used a scoliometer to measure for thoracic and lumbar spine rotation (Bunnell test) [12]. Patients with a straight spine and no truncal rotation were not asked to present for spine radiographs.

\section{Radiologic confirmation of the spine deformity}

Spine radiographs of all patients with clinical signs of scoliosis have been performed with the exception of one with Turner syndrome and another who had undergone deep Xray therapy. Both were skeletally mature at the time of clinical examination. Standard postero-anterior and lateral complete spine radiographs in the erect posture were reviewed. Images at the time of clinical examination were in a hard-copy form and images after 2002 were in digital format. Cobb angles were drawn by the treating scoliosis surgeons and recorded.

\section{Measurement of progression of scoliosis}

Two patients detected with previously unrecognised spine lateral deviation/trunk rotation were referred to the Scoliosis Clinic in their hospital, and subsequently underwent spine imaging every six-months to skeletal maturity. A third patient with previously unrecognised spine deformity was skeletally mature and underwent a single spine radiograph. Twenty-four with known scoliosis had undergone similar regular follow-up in Scoliosis Clinics, prior to clinical examination in this study (two continued follow-up after the 2002 clinical examination). Follow-up spine imaging ceased when patients became skeletally mature or Human Growth Hormone treatment ceased. An increase in Cobb angle of $10^{\circ}$ was the minimum measurement used to define progression of scoliosis.

\section{Ethics}

Institutional Ethics approval was granted from four hospitals in three Australian States to clinically examine all their patients treated through the OZGROW program.

\section{Statistical analysis}

This study produced subgroups with data that could be analysed using a chi-square comparison (Student's t-test). Factors that might theoretically influence the presence or progression of scoliosis including the age of commence-

Table 3: Turner syndrome scoliosis (non-congenital)

\begin{tabular}{ll}
\hline Scoliosis & Karyotype \\
\hline $12^{\circ}$ Right thoracic, hypokyphosis & $45 \times O$ \\
$30^{\circ}$ Right Thoraco-lumbar & $45 \times O$ \\
$18^{\circ}$ Right thoracic, hypokyphosis & 46 XisoX(q10) Mosaic \\
$30^{\circ}$ Right Thoraco-lumbar & $45 \times O$ \\
No Xrays Mild clinical deformity Right thoracic & $45 \times O$ \\
$17^{\circ}$ Left Thoraco-lumbar & $45 \times O$ \\
$18^{\circ}$ Right thoracic, hypokyphosis & $45 X O$ \\
$55^{\circ}$ Right thoracic Scoliosis surgery & $45 X O$ \\
$45^{\circ}$ Right thoracic, hypokyphosis & $45 X O$ \\
$10^{\circ}$ Right lumbar & Diagnosed South Africa. Karyotype not available. \\
$20^{\circ}$ Left Thoraco-lumbar & $45 X O$ \\
$12^{\circ}$ left Thoraco-lumbar & $45 X O / 46 X Y$ mosaic Undiagnosed syndrome \\
$45^{\circ}$ Right Thoracic, hypokyphosis & $45 X O$
\end{tabular}


ment of HGH treatment, the duration of therapy, the magnitude of each dose/average dose of growth hormone and the total amount of growth hormone administered to each patient were included for analysis. Step-wise multiple regression analysis used univariate models for each subgroup, where numbers for comparison exceeded 30 (Table 4).

\section{Results \\ Overall results}

At review in 2001/2002, the mean age of the patients was 13.6 years (range 6-27 years). 91 were male and 94 were female. The mean age at commencement on the OZGROW programme was 8.5 years (range from birth to 12 years, and followed a normal distribution). The mean duration of HGH therapy up to the time of review was 4.7 years (range 2 months to 12 years). The findings from routine clinical and radiological follow-up for those in Scoliosis Clinics ceased in 2006, spanning 4-5 years duration (mean 4.6 years).

\section{Presence of scoliosis}

29 of 185 patients had scoliosis. The duration of HGH therapy and total dose of human growth hormone were not related to the presence of scoliosis, although the average of the first two doses of growth hormone per patient, expressed in milligrams per kilogram body weight, was related to the presence of scoliosis. $(\mathrm{p}=0.021)$. Having Turner syndrome was identified as the only highly significant factor for the presence of scoliosis $(p=0.001)$.

\section{Progression of scoliosis}

The mean duration of HGH treatment for the entire cohort was 4.7 years (SD 2.8). A number of different HGH regimens were administered to the cohort including Saizen $^{\mathrm{TM}}$, Norditropin ${ }^{\mathrm{TM}}$, Somaton ${ }^{\mathrm{TM}}$, Genotropin ${ }^{\mathrm{TM}}$ and Humatropin $^{\mathrm{TM}}$. The mean dose of $\mathrm{HGH}$ treatment was $0.60 \mathrm{mg} / \mathrm{Kg}$ body weight (Range $0.25-1.14 \mathrm{mg} / \mathrm{Kg}$ body weight and SD 0.227). HGH therapy was ceased and restarted at a later stage in 13 children for reasons other than the presence of scoliosis. One male with Cushing's syndrome and mild thoracic scoliosis had a temporary three-month cessation of HGH treatment. HGH therapy was re-started and continued for another two years, with no radiologic progression of scoliosis. Progression of scoliosis was not recorded in two patients with idiopathic scoliosis and two with other conditions, followed up in Scoliosis Clinics between 2001/2 and 2006.

Progression of scoliosis had already occurred in five Turner and two 'other condition' patients at the time of clinical review in 2001/2002 (Cobb angles between $30^{\circ}$ and $55^{\circ}$ ).

Idiopathic short stature and hormone deficiency subgroup Four (3.4\%) of the 117 in this subgroup had scoliosis. All four had idiopathic right thoracic scoliosis less than 20 degrees Cobb angle. Three were male and all were unaware of their scoliosis until they were examined in this study. Two of the males had idiopathic short stature and the other had multiple pituitary hormone deficiency. Two of the three were skeletally mature and the other was age

Table 4: Statistical analysis for the cohort of 185. Predictors of Scoliosis: Logistic Regression - Univariate Models Results

\begin{tabular}{|c|c|c|c|c|c|}
\hline & B & S.E. & Wald & Sig. & $\operatorname{Exp}(B)$ \\
\hline Age Comm. & .039 & .067 & .335 & .563 & 1.040 \\
\hline Duration & -.166 & .099 & 2.814 & .093 & 847 \\
\hline Mg per KgI & 2.544 & 1.277 & 3.965 & .046 & 12.728 \\
\hline $\mathrm{Mg}$ per $\mathrm{Kg} 2$ & 2.420 & 1.122 & 4.656 & .031 & 11.245 \\
\hline $\mathrm{Mg}$ per $\mathrm{Kg} 3$ & .716 & 2.085 & .118 & .731 & 2.046 \\
\hline $\mathrm{Mg}$ per Kg4 & 7.827 & 4.661 & 2.819 & .093 & 2507.794 \\
\hline Last PCTL & -.015 & .016 & .863 & .353 & .985 \\
\hline Turner syndr. & -1.790 & .471 & 14.430 & $<.001$ & .167 \\
\hline First PCTL_Age & -.046 & .076 & .364 & .546 & .955 \\
\hline First_PCTL & -.026 & .024 & 1.255 & .263 & .974 \\
\hline
\end{tabular}

$B=$ Multiple regression co-efficient

S.E $=$ Standard error

Wald (Wald Abraham. Selected papers in statistics and probability. Stanford University Press. New York, Toronto, London. 1955.)

Sig.= Significance

$\operatorname{Exp}(B)=$ Risk ratio

Each variable was used in turn to predict the occurrence of scoliosis in a logistic regression model. The size of the first and second doses of $\mathrm{HGH}$

(MG per KGI and 2) and having Turner syndrome were predictive of having scoliosis. Variables for analysis where numbers exceeded $30-$

a) Age of commencement

b) Duration of $\mathrm{HGH}$ treatment

c) Dose of $\mathrm{HGH}$ in $\mathrm{Mg} / \mathrm{Kg}$ body weight

d) First percentile height at commencement of $\mathrm{HGH}$ treatment (PCTL)

e) Last percentile height at cessation of HGH treatment (PCTL)

f) Presence of Turner syndrome 
13 at the time of clinical examination and continued review in the Scoliosis Clinic of his hospital for three years. The only female in this group had growth hormone deficiency and commenced HGH supplementation at age three years and remained on the OZGROW programme at age 13 years (in 2001). Both who continued clinical review demonstrated no radiologic progression of their scoliosis, from 2001/2 to 2006 .

\section{Turner syndrome subgroup}

Of 45 with Turner syndrome, one had congenital scoliosis and underwent scoliosis surgery at age 13 . Curve progression was not recorded for this patient. Thirteen of the 45 $(28.8 \%)$ had scoliosis radiologically indistinguishable from idiopathic scoliosis (Figures 1, 2, 3). The mean age at diagnosis of scoliosis was 13 (range 3-22 years). All had oestrogen supplementation for delayed puberty. The site/morphology of the scoliosis and karyotype was recorded (Table 3). One had scoliosis prior to the commencement of HGH treatment and two others were diagnosed with scoliosis within one year of commencing the HGH treatment programme. The deformity subsequently progressed in both, resulting in right thoracic curves of $45^{\circ}$. Another underwent surgery for the scoliosis deformity, during HGH treatment. Analysis of the Turner syndrome subgroup revealed that they were administered a larger average dose of growth hormone (milligrams per kilogram body weight $)(\mathrm{p}=0.003)$ and were commenced on the OZGROW program at an earlier age $(\mathrm{p}<0.001)$ than the group comprising idiopathic short stature. The magnitude of the scoliosis curve in Turner syndrome was not influenced by the duration of HGH therapy.

\section{Other syndromes known to be associated with the presence of scoliosis}

Scoliosis was present in 11 of the other 23 (48\%) with varying other syndromes (Refer Table 1). One of this group had kypho-scoliosis.

\section{Growth velocity}

There was a significant statistical correlation between the first and last percentiles of height in the idiopathic short stature and hormone deficiency subgroup ( $\mathrm{r}=0.514, \mathrm{p}<$ $0.001)$ - ie. an acceleration of growth rate compared to peers was not statistically evident on the growth charts, between the commencement of the human growth hormone treatment programme and its cessation. The growth velocity of the four with scoliosis (mean $8.3 \mathrm{~mm} / \mathrm{year}$ range 7.0 to 10.6 ) in the idiopathic short stature and hormone deficiency subgroup was no different from the other 113 in the subgroup (mean $9.0 \mathrm{~mm} /$ year, standard deviation 7.53).

\section{Discussion \\ Prevalence of scoliosis on the Human Growth Hormone treatment programme}

In this study, the 97 patients with idiopathic short stature had a similar prevalence of idiopathic scoliosis to a control Caucasian population [13] and served as a 'control' group for comparisons with the other groups. The prevalence of scoliosis in this study was similar to previously published research, involving 31,462 patients on Human Growth Hormone treatment programmes [14-18]. Scoliosis is not a specific feature of idiopathic short stature and its prevalence should mirror that of the control population [19]. Although scoliosis has been extensively reported in specific syndromes associated with short stature, the commonest spinal deformity in short-stature syndromes and skeletal dysplasias is kyphosis [19].

\section{Prevalence of scoliosis in Turner syndrome on the HGH treatment programme}

The $28.8 \%$ prevalence of scoliosis in Turner syndrome from this study was higher than previously published research, which includes those not treated with HGH (11$12 \%$ ) [20-22]. In a previous HGH treatment study, a 'subgroup with Turner syndrome and those with a history of brain tumour or vertebral abnormalities had a higher prevalence of new and/or severe scoliosis than other groups'[15]. In a larger HGH treatment study, 72 of 24,000 children were diagnosed with scoliosis, of whom 10 had Turner syndrome [16].

\section{Progression of scoliosis on the Growth Hormone treatment programme}

In this study, prospective follow-up from the four with scoliosis and idiopathic short stature/hormone deficiency indicated that there was no progression of the scoliosis during HGH treatment. The deformities in the current study were mainly single curve thoracic scoliosis and the results are similar to those of a previous study involving four single curves [9]. In the previous study, progression of scoliosis was associated with six double curves during HGH treatment, however it was not stated whether there was a temporary/permanent cessation of HGH treatment at the time of scoliosis progression [9].

In this study, retrospective data from the Turner syndrome patients' medical records indicated that the scoliosis deformity progressed in five of thirteen during HGH therapy and that the HGH treatment was not stopped because of this scoliosis progression.

\section{Growth velocity and progression of scoliosis}

In this study, the growth velocity was similar in patients with and without idiopathic scoliosis. This result contrasts with that of a previous study, where accelerated growth 


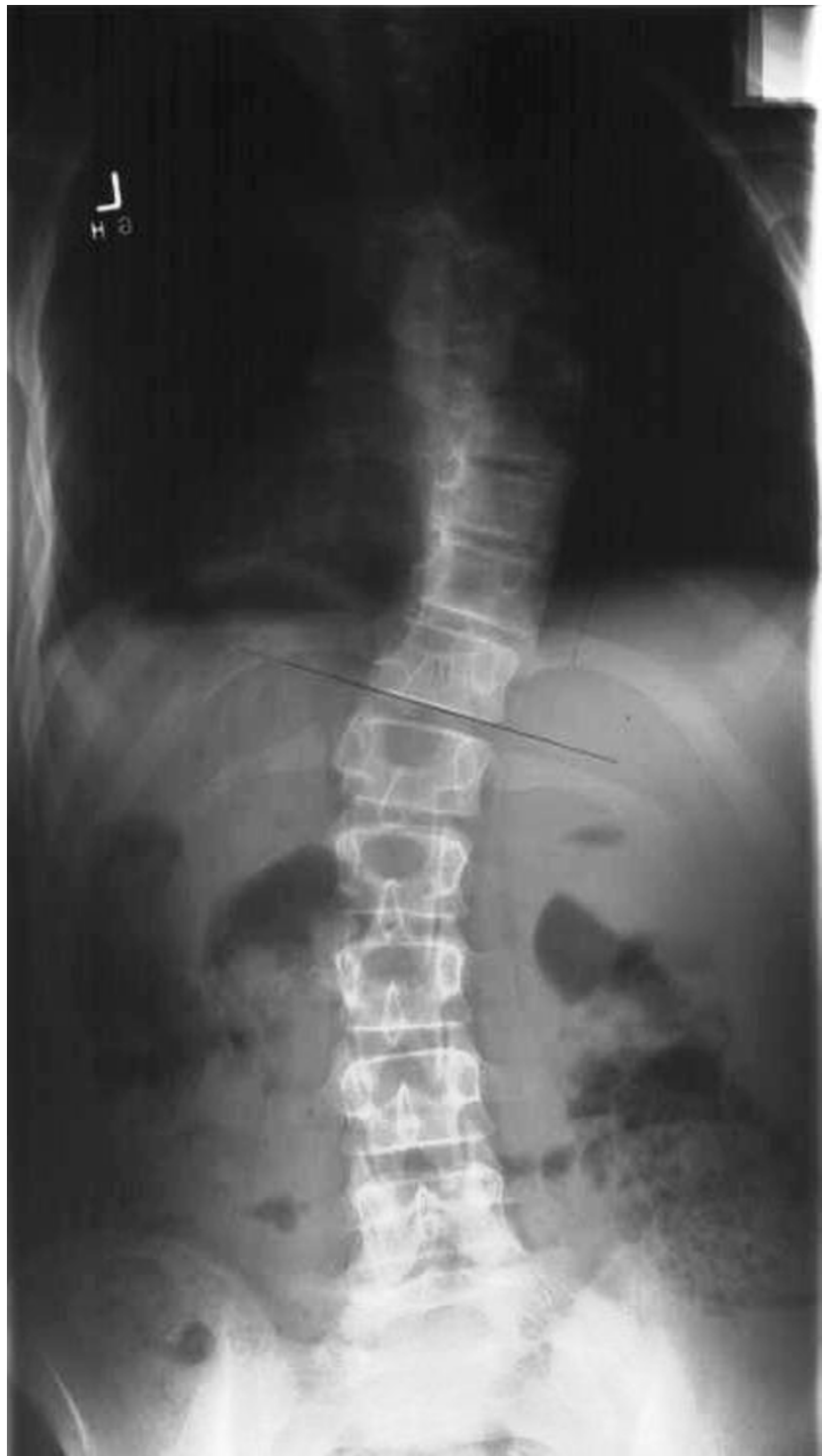

Figure I

PA plain radiograph Turner syndrome scoliosis.

was recorded in eight of ten with scoliosis compared to those without scoliosis [9].

\section{Conclusion}

This study supports the contention that the administration of Human Growth Hormone to a diverse group of short-statured children does not lead to an increased prevalence of scoliosis. An accelerated growth rate during HGH treatment was not recorded in the small numbers with idiopathic scoliosis, contrasting with the results of the only other similar previous study. In this study, patients on HGH treatment with progressive scoliosis had syndromes in which the presence of scoliosis is commoner than an age-matched population.

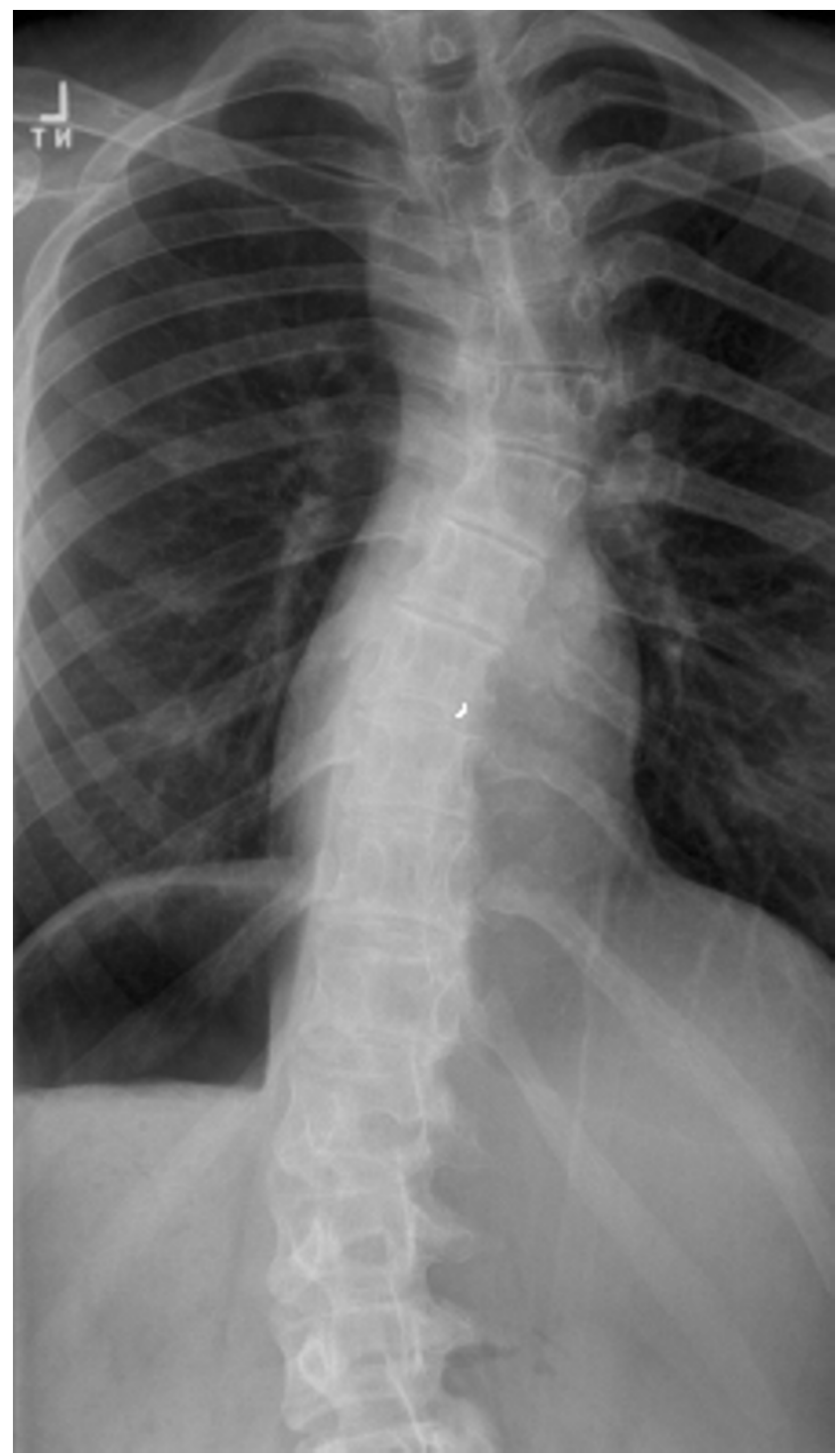

Figure 2

PA plain radiograph Turner syndrome scoliosis.

A curious incidental finding was the $28.8 \%$ prevalence of scoliosis in Turner syndrome, which could mean that scoliosis is commoner in Turner syndrome than previously believed or that treating Turner syndrome girls with human growth hormone leads to an increased prevalence of scoliosis.

\section{Authors' contributions}

This study was completed in the Institutions of the authors and those acknowledged. J B and F T were PhD Principle Advisors and I McP was Associate Advisor. All authors read, edited and approved the final manuscript. 


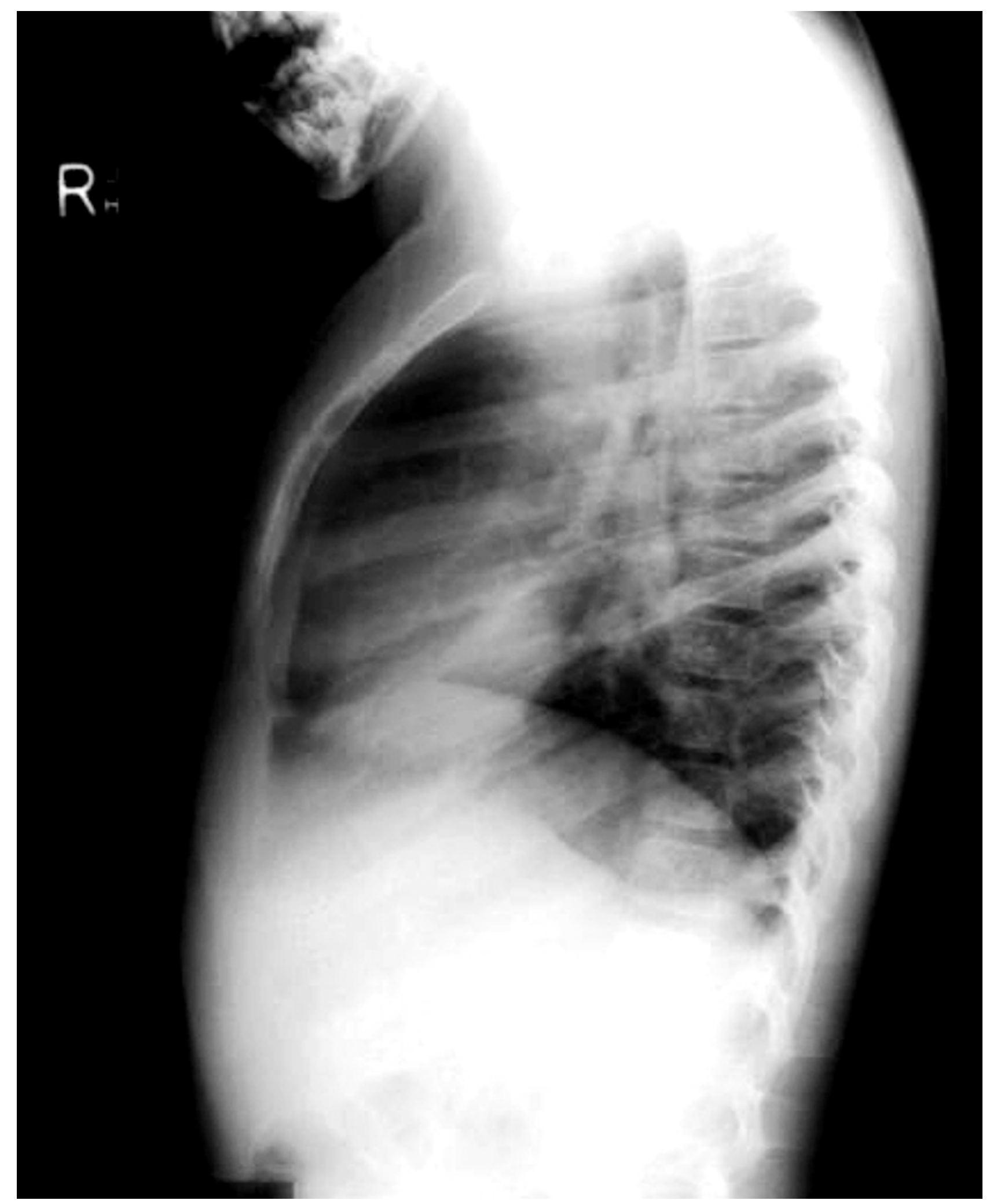

Figure 3

Lateral plain radiograph Turner syndrome scoliosis with hypokyphosis.

Page 7 of 8 


\section{Additional material}

\section{Additional file 1}

Growth Rates and the Prevalence and Progression of Scoliosis in shortstatured children on Australian Growth Hormone Treatment Programmes. The data provided represent the statistical analysis of doses of growth hormone, absolute and relative growth rates and the presence, progression and magnitude of scoliosis.

Click here for file

[http://www.biomedcentral.com/content/supplementary/17487161-2-3-S1.pdf]

\section{Acknowledgements}

The authors wish to thank Dr. R. Kattaranga and Mr P Cundy (South Australia), Mr A J Geddes and Dr B Brankoff (Western Australia), Dr M Thomsett, Dr A Cotterill and H Mercer (Queensland) and especially Mrs Maree Grant (Western Australia), without whom this study could not have been completed. Dr C Swanson (University of Queensland) provided Statistical Analysis.

This study was partly funded by a $\$ 7000.00$ grant from the Australian Orthopaedic Association Research Foundation. (\#008RF).

\section{References}

I. Willner S: A Study of Growth in Girls with Adolescent Idiopathic Structural Scoliosis. Clin Orthop Rel Res 1974 101:I29-135.

2. Nissinen M, Heliovaara M, Seitsamo J, Poussa M: Trunk asymmetry, posture, growth and risk of scoliosis. A three-year follow-up of Finnish prepubertal school children. Spine 1993, 18:8-13.

3. Skogland LB, Miller JAA: Growth Related Hormones in Idiopathic Scoliosis. Acta Orthop Scand 1980, 5 I:779-789.

4. Willner S, Nilsson KO, Kastrup K, Bergstrand CG: Growth Hormone and Somatomedin A in Girls with Adolescent Idiopathic Scoliosis. Acta Paediatr Scand 1976, 65:547-552.

5. Ahl T, Albertsson-Wikland K, Kalen R: Twenty-four-hour Growth Hormone Profiles in Pubertal Girls with Idiopathic Scoliosis. Spine 1988, 13(2): |39-142.

6. Misol S, Ponseti IV, Samaan N, Bradbury JT: Growth Hormone Blood Levels in Patients with Idiopathic Scoliosis. Clin Orthop and Related Research 1971, 81:122-125.

7. Yamada K, Yamamoto H, Nakagawa Y, Tezuka A, Tamura T, Kawata S: Etiology of Idiopathic Scoliosis. Clin Orth Related Research 1984, I84:50-57.

8. Dymling J, Willner S: Progression of a Structural Scoliosis During Treatment with Growth Hormone. Acta Orthop Scand 1978 49(3):264-268.

9. Wang ED, Drummond DS, Dormans JP, Moshang T, Davidson RS, Gruccio D: Scoliosis in Patients Treated with Growth Hormone. J Ped Orthop 1997, I 7:708-7I I.

10. Lyon A, Preece M, Grant D: Growth charts for girls with Turner syndrome. Arch Dis in Childhood 1985, 60:932-935.

II. Adams W: Lectures on curvatures of the spine. Lecture IV. In Lateral curvature of the spine, External characters and morbid anatomy London, Churchill; 1865:89-121.

12. Bunnell W: An objective criterion for scoliosis screening. J Bone Joint Surg 1984, 66 A: I 38I-1387.

13. Rogala E, Drummond D, Gurr I: Scoliosis: Incidence and natural history. J Bone Joint Surg 1978, 60A:173-176.

14. Cowell CT, Dietsch S: Adverse Events During Growth Hormone Therapy. J Pediat Endocrinology Metabolism 1995, 8:243-252.

15. Blethen SL: Monitoring Growth Hormone Treatment: Safety Considerations. The Endocrinologist CME Review Article \#27 1996:369-374.

16. Allen DB: Safety of Human Growth Hormone Therapy: Current Topics. J Pediatrics 1996, I 28(5):S8-SI3.
17. Wilton P: K I G S: Adverse Events Report No I I. Pharmacia International growth Database. To August 2000.

18. Quigley C, Gill A, Crowe B, Robling K, Chipman J, Rose S, Ross J, Cassoria F, Wolka A, Wit J, Rekers-Mambarg L, Cutler G: Safety of growth hormone treatment in pediatric patients with idiopathic stature. J Clin Endocrinol Metab 2005, 90:5I88-5I 96.

19. Tolo V: Spinal deformity in short-stature syndromes. Instr Course Lect 1990, 39:399-405.

20. Lippe B: Turner Syndrome. Endocrinology and Metabolism Clinics of North America 199|, 20:121-I52.

21. Kim J, Rosenfeld S, Keyak J: Increased prevalence of scoliosis in Turner Syndrome. J Ped Orthop 200I:765-766.

22. Smith DW, Jones KL: Recognizable Patterns of Human Malformation. Third edition. W B Saunders Company; 1988:72.
Publish with Biomed Central and every scientist can read your work free of charge

"BioMed Central will be the most significant development for disseminating the results of biomedical research in our lifetime. "

Sir Paul Nurse, Cancer Research UK

Your research papers will be:

- available free of charge to the entire biomedical community

- peer reviewed and published immediately upon acceptance

- cited in PubMed and archived on PubMed Central

- yours - you keep the copyright
BioMedcentral 